\title{
Estética apofática y hermenéutica del misterio: elementos para una crítica de la visibilidad
}

\author{
AMADOR VEGA \\ Departament d'Humanitats \\ Universitat Pompeu Fabra (Barcelona) \\ amador.vega@upf.edu
}

Resumen: Las diferentes hermenéuticas de la negatividad, a lo largo del siglo Xx, dan qué pensar respecto de las deudas espirituales contraídas con la tradición de la teología negativa y, en particular, con las grandes corrientes místicas de la Europa medieval. Se propone el uso del término técnico "estética apofática" (o negativa) para dar expresión a la obra de algunos artistas del siglo Xx, quienes serían los herederos de aquellas tradiciones. Se estudia, como un caso especialmente relevante, una pintura de Mark Rothko (19031970), en quien se dan cita algunos de los motivos centrales de la experiencia religiosa moderna. La hermenéutica de la negatividad se presenta, pues, como preámbulo a una estética apofática de raíz ascético-mística, a partir de una nueva realidad histórica en la que la diferencia sagrado-profano ya no parece válida.

Palabras clave: abstracción, mística, Rothko, nihilismo

\begin{abstract}
Throughout the twentieth century different hermeneutics of negativity helped reflect on the spiritual debts to negative theology, and in particular to the major mystical trends of Medieval Europe. The technical term "Apophatic (or negative) Aesthetics" is proposed to define the work of some twentieth-century artists, who are considered the heirs of these traditions. In this article, a painting by Mark Rothko (1903-1970) is studied. In it some central motifs of the modern religious experience can be traced. The hermeneutics of negativity is to be understood as a preamble to Apophatic Aesthetics, with its ascetic and mystical roots set out from a new historical reality, in which the difference between sacred and profane is no longer significant.
\end{abstract}

Key words: abstraction, mysticism, Rothko, nihilism

En qué medida el arte ha sido a lo largo del siglo xx el lugar en el que las grandes cuestiones de la metafísica se han expresado de un modo directo e impactante es algo que ya Merleau-Ponty puso de manifiesto en su último escrito, a propósito de unas brevísimas observaciones acerca de la pintura de Cézanne. ${ }^{1}$ Por qué razón la representación plástica ha

${ }^{1}$ M. Merleau-Ponty, L'OEil et l'esprit, p. 61. 
asumido los grandes retos de la filosofía es algo que ha quedado registrado en las estrechas correspondencias que se dieron, en los primeros años del siglo pasado, entre el movimiento fenomenológico europeo y las primeras vanguardias artísticas. ${ }^{2}$ La cuestión que hizo posible aquellas correspondencias no podía ser otra que la de la representación y el modelo de realidad que ésta nos ofrece. Pero también en este comienzo del nuevo siglo, aparentemente dominado por los lenguajes laberínticos de la red, continúan siendo las distintas artes las que nos brindan de un modo inmediato planteamientos visuales cuyo impacto sobre nuestra imagen de la realidad no puede ser soslayado.

En lo que sigue voy a intentar sintetizar, en la primera parte, las líneas principales de mis últimos trabajos relativos a lo que he llamado "estética apofática", con la idea de presentar, en la segunda parte, algunas de mis actuales preocupaciones relativas a la elaboración de una antropología de los sentidos a partir de una crítica de la visibilidad.

\section{Estética apofática}

Desde la Antigüedad, los modelos de representación, en la medida en que pudieran referirse a presencias siempre ausentes, han sido objeto de duras controversias cuyo impacto se ha hecho visible en la historia de la cultura occidental. Dichas crisis estuvieron ya presentes en las culturas del Antiguo Oriente y en los sistemas de transmisión doctrinaria relativos al culto a las divinidades. El fenómeno del "aniconismo" es uno de los principales problemas con los que los sistemas teológicos se encontraron, pues al tiempo que pretendían garantizar la pureza de una revelación originaria, se enfrentaban a la imposibilidad de la manifestación sensible que todo sistema religioso lleva implícito. Ya en los comienzos, pues, la doble dimensión sensible/inteligible señalará los distintos discursos, teológicos, filosóficos, artísticos y científicos, hasta el punto que de la conciliación o no de ambos niveles se desprendan modelos de realidad bien diferentes. Pero en los relatos sobre los orígenes no siempre es posible distinguir claramente entre dos planos diferenciados que separen el mundo de los dioses y el de los humanos. Es con la formación de los sistemas religiosos cuando el abismo entre el arriba y el abajo se hace explícito. Para salvar la distancia entre ambos mundos, la creatividad poético-filosófica elaborará complejos modos de

${ }^{2}$ H.-R. Sepp, "Annährungen an die Wirklichkeit. Phänomenologie und Malerei nach $1900 "$ ". 
aproximación a partir de métaforas acerca de dicho estado de separación. No es posible obtener aquí en pocas palabras una imagen que sintetice tal proceso de comprensión de la realidad, en periodos de tiempo muy largos y en culturas tan diversas. Pero si nos remitimos al modelo bíblico, que en gran parte sintetizó las culturas del Oriente Antiguo, podemos observar cómo la prohibición de la representación divina es tratada de modo diverso, dependiendo de los medios de transmisión. Estudios sobre la idolatría en el Antiguo Testamento han puesto de manifiesto por qué estaban prohibidas las representaciones pictóricas de la divinidad y no así las lingüísticas, las cuales permitían expresarse en términos antropomórficos por medio de imágenes poéticas. ${ }^{3}$ De cualquier modo, ha sido la representación plástica la que ha recibido una mayor atención y ha sido objeto de preocupación, mientras que los sutiles juegos del lenguaje poético han permitido soslayar la estrecha mirada de los vigilantes de la ortodoxia.

El fenómeno del aniconismo bíblico constituyó un primer momento de lo que podríamos llamar "hermenéutica de la negatividad", cuyos problemas relativos a lo que puede ser representado o no encontraron su continuidad en las virulentas disputas acerca de los movimientos iconoclastas que afectaron a la civilización bizantina entre los siglos VI y VIII de nuestra era. ${ }^{4}$ En el culto de las imágenes religiosas vemos hasta qué punto el impacto de las doctrinas teológicas en el mundo político, social y artístico fue enorme, pues ponían en evidencia la tensión entre iconodulia e iconoclastia, tensión en la que convergían elementos del pensamiento griego, del judaísmo y del Islam, así como de los numerosos movimientos gnósticos y de las doctrinas dualistas de la Antigüedad tardía. Y a pesar de todo, como dice Belting, por lo que respecta a la pervivencia de los problemas en nuestra historia, contrasta la potencia de las imágenes con la impotencia de la teología. ${ }^{5}$

Aby Warburg, durante los años treinta del siglo pasado, con su idea de Kulturwissenschaft, puso los cimientos para la recuperación del paganismo antiguo con la intención de obtener todo un nuevo pensamiento en imágenes. En cierto modo, el proyecto del Warburg Institute, y de los investigadores que estuvieron asociados a él, en la época de Hamburgo hasta 1933 y posteriormente en Londres, estaba destinado a crear un corpus iconológico como paso previo al surgimiento de las recientes hermenéuticas de la imagen. Para ello había sido preciso hacerse

${ }^{3}$ M. Halbertal y A. Margalit, Idolatría, pp. 57 y ss.

${ }^{4}$ E. Kitzinger, The Art of Bizantium and the Medieval West: Selected Studies (c. V et VII).

${ }^{5}$ H. Belting, Bild und Kult, pp. 11 y ss. 
con los materiales iconográficos que quedaron sepultados por el poder devastador de las doctrinas, lo que ha servido para llevar a cabo lecturas paralelas de texto e imagen, que tan importantes resultados nos han proporcionado. Todavía no se ha escrito una historia completa de aquel inmenso proyecto y debemos, una y otra vez, hacernos cargo de la originalidad de la mirada de aquellos hombres sobre los materiales de la historia del espíritu. ${ }^{6}$ De hecho, puede decirse que Aby Warburg recogía el legado del joven Nietzsche, quien en su obra de juventud, $E l$ nacimiento de la tragedia (1872), postulaba la necesidad de un nuevo pensamiento en imágenes. Aunque en aquellos años su doctrina sobre la "muerte de Dios" no había sido formulada todavía, el camino ya quedaba trazado: la muerte y renacimiento del dios Dionisos llamaba a una filosofía fundada en los instintos, y se proponía desterrar la idea del dios de la metafísica.

Ha sido Heidegger, sin embargo, quien ha desentrañado el significado profundo de aquella experiencia del pensamiento, en relación precisamente con el mundo de las representaciones, como el último estadio de la metafísica. Pero la destrucción de aquella concepción del Dios cristiano, procedente de la tradición neoplatónica y del dualismo subyacente en ella, que el propio Heidegger se encargó de denunciar en su curso de 1920/1921 en la Universidad de Friburgo, ${ }^{7}$ no tiene su origen exclusivamente en Nietzsche, ni en la filosofía moderna, pues no es posible elaborar una teoría de la subjetividad sin atender a los modelos de la vida interior que surgieron en la Europa medieval, entre finales del siglo XII con Hildegard von Bingen y los movimientos de la llamada mística femenina, y el siglo XIV con su más fuerte expresión en la teología mística de la escuela alemana, muy particularmente en los sermones del Maestro Eckhart. ${ }^{8}$

Si el mundo moderno puede caracterizarse por una clara conciencia de la subjetividad, que alcanza sus formulaciones más evidentes en las filosofías racionalistas del siglo XVII, hay que insistir una vez más en que todo ello no es sino el resultado de lentos procesos de secularización iniciados un siglo antes por Lutero y sus lecturas de Ockham y de los místicos alemanes, a través de los sermones de Johannes Tauler. En la obra de estos autores, que cada vez conocemos mejor gracias a las ediciones críticas en curso, se halla el germen de toda una crítica de la religión dirigida a ahuyentar el fantasma de la idolatría en for-

${ }^{6}$ F. Saxl, "La historia de la Biblioteca de Warburg (1886-1944)".

${ }^{7}$ M. Heidegger, Phänomenologie des religiösen Lebens, pp. 37 y ss.

${ }^{8}$ V. Cirlot y B. Garí, La mirada interior. Escritoras mística y visionarias en la Edad Media, pp. 13 y ss. 
mulaciones como aquella del Maestro Eckhart: "ruego a Dios que me vacíe de Dios". ${ }^{9}$ En cuanto crítica de la religión, la mística alemana tensaba la cuerda de la ortodoxia con un lenguaje lleno de lo que se ha denominado "las imágenes explosivas de Dios". ${ }^{10}$ No en vano algunos autores han creído ver en esa filosofía mística los orígenes del nihilismo moderno; pero si nos acercamos a los detalles de ese incipiente lenguaje filosófico en lengua vernácula, apreciaremos cómo la misma tradición doctrinaria que quiere reformarse ofrece los elementos para su regeneración, de modo que tradición y ruptura terminen por configurar dos momentos de un mismo movimiento del espíritu. En efecto, el lenguaje de la negatividad, tan presente en los textos de la mística alemana, tenía sus orígenes en la "teología mística" del Corpus Dionysiacum, conjunto de libros y cartas atribuidos a un monje sirio del siglo VI, que se presentaba a sí mismo como discípulo de san Pablo. Este teólogo establecía la diferencia, para referirse a la divinidad, entre la "vía afirmativa" (katafatiké), que permitía atribuir propiedades precisas a Dios, y la "vía negativa" (apofatiké), en un grado superior, que reconocía la imposibilidad de tener un conocimiento objetivo y conceptual de la divinidad. En este sentido podemos decir que la vía negativa se encuentra en los orígenes de un "nihilismo religioso" o de lo que Nishitani llamó una "nihilidad absoluta" - para distinguirla de aquella "nihilidad relativa" de Nietzsche-, en su enorme esfuerzo por entender a los místicos alemanes desde los motivos fundamentales de la tradición zen. ${ }^{11}$

El enorme éxito del método empleado por la vía negativa se pone en evidencia en los complejos caminos que siguió, entre los siglos XIV y XVII, dicho modo del discurso, en una historia paralela a la historia de la filosofía moderna, y que se inicia ya en el mismo siglo XIV, con los seguidores de Eckhart en Alemania: Heinrich Seuse y Johannes Tauler. Éste último fue predicador en Estrasburgo, y Ruusbroec, procedente de los Países Bajos, parece que recogió de él algunas ideas; estos mismos sermones de Tauler llegaron a España en la traducción latina de Surius que san Juan de la Cruz leyó; y tras la muerte de éste, sus obras se editaron por primera vez en Francia. Si leemos el Peregrino querúbico, la obra más importante de Angelus Silesius, autor espiritual del barroco alemán, tan leído por escritores y poetas, encontramos citadas en el proemio a todas estas autoridades como sus fuentes de inspiración. Lo que empezó en el siglo XII en los países germánicos, retornó allí

\footnotetext{
${ }^{9}$ Maestro Eckhart, El fruto de la nada, p. 77.

${ }^{10}$ A.M. Haas, "Las imágenes explosivas de Dios".

${ }^{11}$ K. Nishitani, La religión y la nada.
} 
en el XVII habiendo atravesado el sur de Europa, configurando lo que Kolakowski denominó una "internacional mística". ${ }^{12} \mathrm{Y}$ es que aquellas formas de la negatividad están también en los orígenes de la filosofía romántica alemana, muy especialmente en la filosofía de Schelling, de Hegel $^{13}$ y en la herencia estética posterior, especialmente en la obra de T.W. Adorno. ${ }^{14}$

Que la capacidad creativa de aquellos hombres y mujeres que escribieron en lengua vernácula está en el fundamento del pensamiento moderno occidental es algo que se hace evidente en la obra de Heidegger, quien, al igual que Hegel lo hiciera con Jacob Böhme (siglo XVI), reconoció en Eckhart una fuente de su propio pensamiento. ${ }^{15}$ Pero lo mismo podríamos decir de otros filósofos como Simone Weil o, más recientemente, Jacques Derrida, que en junio de 1986 dedicó a Eckhart una conferencia en Jerusalén, con el título: "How to Avoid Speaking", y que representa uno de los ensayos más interesantes de hermenéutica de la negatividad de las últimas décadas. ${ }^{16}$

Sin embargo, la negatividad como forma del discurso se halla también presente en el arte de las vanguardias europeas, en virtud de los modos de destrucción del lenguaje de las imágenes. Es así como, por ejemplo, la pintura de Braque y Picasso supuso una ruptura fundamental en lo que respecta a la concepción de la realidad visible. Lo que la pintura cubista expresa ha sido considerado como una manifestación precisa de la filosofía fenomenológica, la cual había comenzado su andadura en 1900 con la publicación de las Investigaciones lógicas de Husserl. ${ }^{17}$ Pero ya antes, uno de los pioneros de la abstracción pictórica, Kandinsky, había estado trabajando en la reforma del mundo espiritual de su época a partir de todo un nuevo mundo de formas, como dejó por escrito en algunos de sus libros, especialmente en De lo espiritual en el arte (1912). ${ }^{18}$ Desde entonces, la abstracción asumió, en muchos aspectos, la tradición espiritual anterior, aunque en una perspectiva que

${ }^{12}$ Véase M. de Certeau, La Fable mystique, pp. 156 y ss; C. Ossola, "Caminos de la mística: siglos XVII-XX", pp. 13-62, y L. Kolakowski, Chrétiens sans Église. La conscience religieuse et le lien confessionel au XVII siècle.

${ }^{13}$ E. Benz, Les Sources mystiques de la philosophie romantique allemande, pp. 11 y ss.

${ }^{14}$ P.V. Zima, La Négation esthétique, pp. 133-177.

${ }^{15}$ A.M. Haas, Kunst rechter Gelassenheit, pp. 247-269.

${ }^{16}$ J. Derrida, Cómo no hablar.

${ }^{17}$ H.-R. Sepp, op. cit.

${ }^{18}$ Para el ambiente en que se desenvolvió el mundo de Kandinsky, véanse los trabajos presentados en el catálogo de la más reciente exposición: Annegret Hoberg, Kandinsky. Absolut. Abstrakt. 
podríamos denominar con Bataille "a-teológica" y que ha encontrado eco en la obra del filósofo Mark C. Taylor, quien identifica una vía negativa en el arte moderno y contemporáneo, a partir de presupuestos filosóficos de lo que ha llamado: "theoesthetics". Más recientemente ha hablado de un doble movimiento de "creación-destrucción" (figuracióndesfiguración), característico del cristianismo y de los procesos de secularización ligados a él. La capacidad figurativa y desfigurativa del arte nos advierte de una estructura latente en las sociedades globales, donde la polaridad entre los dos términos, religión-secularidad, queda en cierto modo superada por una coimplicación de ambos al modo en que lo hacen los sistemas de networks. ${ }^{19}$

Nuestra hipótesis parte del empleo ampliado del término técnico apofatiké a la estética, de ahí "estética apofática o negativa", ${ }^{20}$ pero más que a las estéticas negativas surgidas en el pensamiento contemporáneo, en las que la negatividad constituye un momento autónomo en virtud de la peculiar situación del sujeto moderno, nuestra "estética apofática", que recupera el término griego por su vocación contemplativa, requiere una comprensión de la negatividad entendida como una vía ascética del pensamiento, con la idea de disponer de un campo de visión de la realidad que consiga evitar los límites conceptuales sujetos al campo semántico de lo trascendente-inmanente. Todo ello, teniendo presente que una estética apofática no es más que el momento ascético de una entera antropología de los sentidos, en su doble dimensión sensible/inteligible. Ahora bien, una "estética apofática", aun cuando hunde sus raíces en la negatividad y se presenta como una ascética, no niega el necesario carácter perceptivo de la sensibilidad; antes bien, desarrolla una entera sensualidad surgida de la contención propia del momento ascético, con la única intención de dar mayor expresión sensible a lo que emerge o aparece frente a los sentidos. ${ }^{21}$ Una estética

${ }^{19}$ M.C. Taylor, Disfiguring. Art, Architecture, Religion, pp. 17 y ss, y After God, pp. 13 y ss.

${ }^{20}$ Utilicé por primera vez esta expresión en mi artículo: "El sacrificio de la imagen. Ideas para una estética de la religión" (Er. Revista de Filosofía, no. 19, pp. 130146), posteriormente incorporado como capítulo: "La imatge nua de Déu: apunts d'estètica negativa", en A. Vega, Passió, meditació i contemplació. Sis assaigs sobre el nihilisme religiós, y en castellano: "La imagen desnuda de Dios: apuntes de estética apofática”, en Zen, mística y abstracción. Seis ensayos sobre el nihilismo religioso. Hago una aplicación más amplia de estas ideas en mi libro Arte y santidad. Cuatro lecciones de estética apofática.

${ }^{21}$ El proyecto de desarrollar una antropología de los sentidos espirituales se remonta a mi estudio Ramon Llull y el secreto de la vida. Años más tarde hice una aplicación de estas ideas en mi Tratado de los cuatro modos del espíritu. 
apofática se corresponde con el momento destructor de todo proceso creador, razón por la cual aquí la negación es sólo un momento previo a la afirmación. Toda teoría estética en cierto modo debe ser una teoría de la respuesta, provocada por la emergencia de aquello que maravilla o aterroriza y que, desde Rudolf Otto, ha sido asociado a lo sagrado. Por todo ello, en una época en la que lo sagrado parecía haberse ocultado en lo profano, ${ }^{22}$ se hace necesario obtener una gramática de lo sagrado ausente, a partir del análisis de la obra de arte, con la intención de disponer de una hermenéutica y de una estética como fundamentos de una antropología de los sentidos.

Si en un primer momento se ha presentado una breve historia de la negatividad en el pensamiento occidental, de modo que nuestra idea de negatividad sea entendida en el contexto ascético-místico que le corresponde, ahora deberíamos estar en condiciones de elaborar una gramática de las imágenes que den cuenta de una estética apofática. Si, como dice Taylor, la secularización es un fenómeno religioso, ${ }^{23}$ sería un error pensar que en nuestro mundo secularizado no se da una presencia de lo que los historiadores de la religión han denominado "lo sagrado", en el sentido de "numinoso" al que se refería Rudolf Otto en Lo santo de 1916. El término sagrado, a pesar de la carga de significados que conlleva, ha sido ciertamente integrador de contenidos referentes al ámbito de la religión, dado que el mismo Mircea Eliade, Thomas Altizer ${ }^{24} \mathrm{y}$ Taylor, siguiendo la estela de la obra de Paul Tillich, han destacado el aspecto ambiguo de tal término en el que converge también la dimensión de lo profano. De todos modos, y de cara a una estética no religiosa ni teológica, aunque con elementos ascético-místicos muy importantes, prefiero hablar de una "hermenéutica del misterio" (o del "secreto"), en la medida en que este término está ya presente en la palabra mística. La dificultad de aceptarlo se manifiesta en muchos autores actuales por su connotación teológica, pero soy de la opinión que no es otra cosa lo que acaba por abarcar términos alternativos como "Aura" (Benjamin) y "Ereignis" (Heidegger), que configuran el centro de reflexión de los trabajos de Dieter Mersch acerca de una "estética de lo performativo". ${ }^{25}$ Una hermenéutica del misterio se inspira también en lo que Michel de Certeau llamó "secreto", en la medida en que no hay hermenéutica sin secreto que descubrir, ni estética sin misterio, o sin silencio que se haga

${ }^{22}$ M. Eliade, "Permanencia de lo sagrado en el arte contemporáneo", en El vuelo mágico, pp. 139-146.

${ }^{23}$ M.C. Taylor, After God, pp. 43 y ss.

${ }^{24}$ T.J.J. Altizer, Living the Death of God. A Theological Memoir.

${ }^{25}$ D. Mersch, Was sich Zeigt. Materialität, Präsenz, Ereignis y Ereignis und Aura. 
presente. ${ }^{26}$ Lo apofático aquí es lo que surge y se presenta, aunque en su calidad silente, oscura o vacía, según las metáforas que la tradición mística ha sabido emplear, para no quedar justamente condenada al silencio. Una hermenéutica del secreto o del misterio debería constituir el preámbulo a toda estética apofática.

Los artistas de las primeras vanguardias europeas ofrecieron un material, tanto pictórico como escrito, para una valoración del ambiente espiritual de la primera mitad del siglo Xx, en la que se descubren los estrechos vínculos, por ejemplo, del pensamiento de Kandinsky con las ideas elaboradas por Rudolf Steiner y el movimento teosófico. ${ }^{27}$ Pero las condiciones filosóficas y religiosas de las últimas décadas, cuyas ideas se fueron elaborando mucho antes, exigen un nuevo análisis de esos mismos materiales a la luz de las nuevas condiciones que han creado una mirada que escapa a la polarización sagrado-profano. El caso es que en las últimas décadas la escena del arte habla y se expresa en contenidos y formas que nos recuerdan a las de un periodo anterior a la aparición del arte, entendido éste como un momento de separación del mundo cultual. Hemos de educar la mirada que nos permita desbrozar el camino por el que, como decía Heidegger, han huido los dioses, con la intención de saber si aquello que vemos es la huella de algo siempre ausente o si estamos en condiciones de reconocer nuevas epifanías. ${ }^{28}$ De ahí que se haga también urgente empezar a desarrollar una nueva antropología de los sentidos que nos permita hacernos cargo de una realidad ni sagrada ni profana, en la que el arriba y el abajo, lo sensible y lo inteligible, lo visible y lo invisible, no habiten lugares diferentes.

Mientras que la primera obra abstracta realizada por Kandinsky se asocia a una exploración de procesos morfológicos, a partir del análisis de la geometría y los colores, con la finalidad de hacer posible una primera visibilidad de lo invisible, ${ }^{29}$ fue el "expresionismo abstracto" de la Escuela de Nueva York el que, desde un punto de vista antropológico, completó la exploración iniciada con la abstracción europea. La mayor parte de sus miembros (Barnet Newman, Jackson Pollock, Cliford Still o Mark Rothko) sintieron la necesidad urgente de explorar el pasado

${ }^{26}$ M. de Certeau, op. cit., pp. 132-137.

${ }^{27}$ B. Gruber, "Mystik, Esoterik, Okkultismus: Überlegungen zu einer Begriffsdiskussion", y Martina Wagner-Egelhaaf, "Die mystische Tradition der Moderne. Ein unendliches Sprechen".

${ }^{28}$ M. Heidegger, "Wozu Dichter?", p. 268.

${ }^{29}$ M. Henry, Ver lo invisible. Acerca de Kandinsky.

Diánoia, vol. LIV, no. 62 (mayo 2009). 
mitológico de la cultura. ${ }^{30}$ En sus pinturas aflora de nuevo la fuerza del inconsciente del artista, todo un mundo de sueños, que se asienta sobre los complejos procesos de configuración de lo humano-divino característicos de la Antigüedad. El pintor se ve a sí mismo como un arqueólogo que explora las profundidades de la historia para encontrar una luz que le permita avanzar a través de la densidad de su propio tiempo. Los vínculos del surrealismo con las obras de muchos de los pintores de dicha escuela son evidentes y no hacen sino confirmar el espíritu de búsqueda y asunción de aquellas formas que la Tiefenpsychologie ya había iniciado por su parte: el elemento siempre ambiguo e inquietante de la imagen situada en el límite de lo sagrado y de la profanación, con el fin de explorar la capacidad de la imagen para acoger el misterio o lo sagrado. ${ }^{31}$ Los límites de la representabilidad del misterio fueron explorados en los años cincuenta por el filósofo italiano Enrico Castelli, en una obra rara y ella misma llena de misterio, quien desarrolló una hermenéutica de lo sagrado cuyos principios de comprensión de la imagen se remontaban a las obras de los pintores-teólogos flamencos, como El Bosco, y a los textos de los místicos renanos. ${ }^{32}$

Este carácter ambiguo del misterio y lo sagrado está presente también en la pintura del artista catalán Antoni Tàpies, especialmente en la década de los años cuarenta, durante el movimiento llamado "tachista"; allí la desfiguración o destrucción de los pintores abstractos anteriores se convierte en provocación, como un elemento más de nuestra gramática de la negatividad, aun cuando en Tàpies el diálogo con las formas de la vacuidad procedentes de las tradiciones asiáticas, especialmente del taoísmo, está muy presente. ${ }^{33}$ Ésta es una manera de hacer extensible dicha hermenéutica a otras tradiciones. Aunque la pintura de Tàpies ofrece materiales suficientes para la elaboración de una hermenéutica de las imágenes, gracias a su potencia, a la vez comunicativa y reflexiva, conviene ampliar el campo de análisis a los espacios plásticos que están más allá de la tela, como es el caso de la escultura. Otras artes podrían aportar materiales interesantes desde su propio lenguaje expresivo (la danza, el teatro, el cine, etc.). Pero la escultura ha sido la que, ya desde los años setenta del siglo veinte, se ha situado en un campo de exploración de lo físico cuya expresión estética difícilmen-

${ }^{30}$ S. Polcari, Abstract Expressionism and the Modern Experience, pp. 33 y ss.

${ }^{31}$ V. Cirlot, Hildegard von Bingen y la tradición visionaria de Occidente, pp. 183206.

${ }^{32}$ E. Castelli, Lo demoníaco en el arte.

${ }^{33}$ A. Vega, "Antoni Tàpies: Negatio, negationis. Un espacio de meditación y silencio", pp. 241-266. 
te se deja explicar sin acudir a una hermenéutica de la negatividad. Las propuestas sobre el vacío de las enormes esculturas en hierro del escultor vasco Eduardo Chillida (1924-2002), integradas en el paisaje de su tierra, evocan una mitología prenarrativa cercana a la de los cultos megalíticos. Ha sido Jorge Oteiza (1908-2003), sin embargo, quien en sus numerosos textos escritos, desde Carta a los artistas de América, hasta su fundamental Quousque tandem..., ha planteado un programa de educación estética levantado, en sus grandes intuiciones, sobre lo que denominó "la desocupación del vacío", y que le llevaron a un consecuente abandono del arte, según aquella actitud ascéticomística que reclamábamos para una estética apofática. La propuesta teórica de Oteiza, por ejemplo, fue desarrollada por el artista como un imperativo, tras haber abandonado la práctica escultórica en el mejor momento de su creación, cuando acababa de recibir el Primer Premio de la IV Bienal de São Paulo en 1957. Este hecho nos lleva a tener que considerar los distintos momentos de abandono en el arte moderno y contemporáneo como una parte más de la vida del arte y de los sacrificios que lleva implícitos. Si la práctica artística puede continuar lejos de la producción artística, indica que los elementos de la negatividad, como "renuncia" y "abandono", continúan teniendo un sentido nada desdeñable en el camino ascético de la vida de artista. En esta misma línea cabría incluir al artista anglo-indio Anish Kapoor, o antes que él a Joseph Beuys, para quienes el arte cumple funciones religiosas o curativas. Pero nuestra exploración no debería detenerse en el arte objetual. Su complemento dinámico lo encontramos en el uso de la cámara de video, al ofrecernos un espacio escénico abierto en el que los aspectos de la negatividad y de la vacuidad se ponen a prueba. Ejemplo de esto es el artista estadounidense Bill Viola, el cual ha desarrollado una obra de significado místico-contemplativo a partir del uso de las nociones de "imagen-movimiento" del filósofo Henri Bergson. Sus repercusiones en la historia del arte más reciente comienzan a ser estudiadas en el contexto de la tradición occidental a la que el artista ha dedicado algunas de sus exposiciones más impresionantes (The Passions, 2003). La obra de Viola pone de relieve la clara voluntad de ofrecer al espectador la posibilidad de vivir la experiencia de la duración de la imagen en tiempo real, de modo que el carácter fantástico de la representación se vea anulado por la presencia de las imágenes como acontecimiento. En sus performances no sólo se propone ver en escena el cuerpo, sino que se explora una mirada peculiar sobre su visibilidad en el tiempo. Los presupuestos filosóficos de la unidad de lo visible y de lo invisible, que dicha obra 
cuestiona, atraviesan la entera fenomenología, desde Husserl a Michel Henry. ${ }^{34}$

Las ideas bergsonianas de la "durée" y de la "image-mouvement", y su puesta en escena por parte de Viola, habría que contrastarlas con la obra del filósofo Gilles Deleuze, no sólo con sus estudios sobre el cine, sino también con su ensayo sobre la pintura de Francis Bacon, donde el tema de la fragmentación de la imagen aparece con toda su fuerza. ${ }^{35}$ Lo que añaden Viola y Deleuze a nuestra mirada sobre el arte es una reflexión sobre el tiempo de esa mirada y los estados de conciencia que se desprenden de la misma, como sucede sin duda en el cine de Wim Wenders. ${ }^{36}$

Si con el "expresionismo abstracto" el cuerpo se vio fragmentado y expulsado de la escena mediante un proceso de desfiguración de la imagen, con las nuevas tecnologías el cuerpo vuelve a la escena, ya sea en su papel de tótem, ${ }^{37}$ o como partícipe en el nuevo espacio interfacial; es cuanto la "endofísica" de Otto Rössler ha propuesto y que correspondería a una estética digital o "endoestética". ${ }^{38}$ Todo ello nos hace pensar en cierto retorno de "lo barroco", en el sentido que dio Eugenio d'Ors a esta categoría, como algo que introducía un "eón", o constante, en la historia del arte, opuesta a lo "clásico". ${ }^{39}$ De nuevo las "formas que vuelan" se opondrían a las "formas que pesan" (D’Ors), como si se tratara de un juego entre la sensibilidad y el intelecto. Pero tengo alguna duda respecto de la ligereza del eón barroco que se avecina. Habría que abrir una discusión a propósito de esta categoría de "lo barroco", en cuanto levedad o en cuanto densidad.

Una vez obtenida cierta visibilidad a propósito del comportamiento de las imágenes a través de sus modos de expresión: fragmentacióndesfiguración (abstracción); profanación-ambigüedad; abandono-vacuidad; duración y movimiento, o levedad-densidad-gravedad, podríamos abordar una fenomenología completa con el fin de obtener una "gramática de las imágenes" que, a su vez, nos proporcionara marcos de significación y, finalmente, un horizonte hermenéutico sobre el cual

${ }^{34}$ Acerca estos artistas mencionados, véase A. Vega, "Mística y estética en el pensamiento de Jorge Oteiza"; y Arte y santidad, pp. 139-159.

${ }^{35}$ G. Deleuze, Cinéma. I. L'image-mouvement, pp. 9 y ss, y Francis Bacon, Lógica de la sensación.

${ }^{36}$ A. Graf, The Cinema of Wim Wenders. The Celluloid Highway, pp. 92-104.

${ }^{37} \mathrm{H}$. Belting, Bild-Anthropologie: Entwürfe für eine Bildwissenschaft.

${ }^{38}$ C. Gianetti, Estética digital. Sintopía del arte, la ciencia y la tecnología, pp. 168 y ss.

${ }^{39}$ E. D’Ors, Lo barroco.

Diánoia, vol. LIV, no. 62 (mayo 2009). 
situar la cuestión relativa a la tensión entre lo visible y lo invisible. Una crítica de la visibilidad debería poder destilar la densidad representacional de los media, a partir de un análisis de lo que Jean-Luc Marion ha llamado los "fenómenos saturados" ${ }^{40}$ La saturación se asocia de manera inmediata a la ambigüedad de la que ya se ha hablado: la tensión entre luz y oscuridad podría aportar análisis interesantes para una estética apofática, en la medida en que esta estética ha sido expresada comúnmente en la tradición occidental por medio de una simbólica de la luz y las tinieblas.

\section{Hermenéutica del misterio: la pintura de Mark Rothko}

El ejemplo del que me serviré para establecer las distintas estaciones de este trabajo es el de Mark Rothko (1903-1970). ${ }^{41}$ Mi aproximación a este artista se debe a que a lo largo de su extensa obra he creído reconocer una estructura expresiva paralela a la que se da en todo proceso religioso. ${ }^{42}$ Rothko también se interesó por el mito, pues en él vio la esencia trágica del arte. Sus pinturas de los años cuarenta nos muestran obras cuya morfología queda asociada a sus lecturas de aquellos años, especialmente a las tragedias de Esquilo, El nacimiento de la tragedia de Nietzsche y Temor y temblor de Kierkegaard, pero también a la obra del antropólogo inglés sir James Frazer, La rama dorada. Los títulos de sus cuadros como Antígona, Edipo o Ifigenia muestran una clara preocupación por el tema del sacrificio. La desfiguración de los cuerpos humanos corre paralela, podríamos decir, a la fragmentación ritual del cuerpo conocida en los cultos mistéricos. Pero llegó un tiempo en que el artista ya no pudo hacer uso de la figura humana para expresar sus emociones, y ahí es donde da comienzo la que podríamos llamar fase madura de su obra, conocida como "Sectionals", porque muestra de un modo obsesivo, que no abandonará de hecho hasta el final de su vida, unas telas siempre divididas en dos o tres secciones o franjas de colores. Sabemos que Rothko siempre se vio a sí mismo pintando un muro, como los frescos de Pompeya que tanto admiró en sus viajes a Italia. El proceso de desfiguración de la imagen, que terminó en los grandes paneles monocromos de la Rothko Chapel en Houston, había

${ }^{40}$ J.-L. Marion, Du Surcroît. Études sur les phénomènes saturés, pp. 65-98.

${ }^{41}$ Las ideas del artista, que en gran parte vienen aquí comentadas se encuentran en sus escritos: The Artist's Reality. Philosophies of Art y Writings on Art.

${ }^{42} \mathrm{He}$ estudiado con detalle estos aspectos en el capítulo: "Pasión, meditación y contemplación: sobre la desfiguración ritual en el arte de Mark Rothko", de mi libro Zen, mística y asbtracción, pp. 109-129. 
corrido paralelo al de la religión, desde su aspecto más cultual hasta el más contemplativo, donde la desfiguración ritual de la imagen se situaba en los fundamentos de la abstracción. Rothko siempre se manifestó contrario a todo tipo de interpretación de su obra, al defender que el único modo de explicar sus cuadros era mediante una suerte de "matrimonio de mentes" entre el observador y el artista; es decir, un lugar de encuentro en el que la expresividad adquiere un significado emocional, imprescindible para penetrar los misterios de la obra expuesta. El misterio no es algo que se ha de descubrir en un lugar segregado, como es el caso de lo sagrado que se define frente a lo profano. El misterio no ocupa un lugar fuera de la mente del artista y del observador. El único modo de proseguir, por lo tanto, con una hermenéutica de las imágenes pictóricas es superar la noción de obra de arte como un objeto aparte.

La verdad del arte, si utilizamos la expresión de Heidegger en $E l$ origen de la obra de arte (1936/1937), reside en su aparecer, en su emerger, en su abrir espacio en la tierra, al modo de una "apertura al misterio" (Offenheit für das Geheimnis). El arte, para Rothko, no está en la obra, sino en lo que aparece entre la obra y aquel que la observa. De momento conviene, sin embargo, recordar que hemos salido de la obra de arte en su aspecto objetual y que nos hallamos en un escenario de representación en el que los modelos situados en el orden de lo trascendente o invisible han perdido toda dimensión invisible, aunque no para desaparecer definitivamente, sino para hacerse presentes en un escenario en el que no hay espacios secretos. El secreto ya no es algo que debe ser desocultado, sino aquello que debe nacer siempre de nuevo.

A mediados de los años cincuenta, con las series de pinturas conocidas como "Sectionals", Mark Rothko había dado ya con un lenguaje propio en su labor creativa: los cuadros nos muestran diferentes secciones, mayormente espacios rectangulares, cuyas variaciones de color constituyen el complemento único de su expresión. Espacio y color serán los únicos elementos de este lenguaje, a partir de los cuales el artista desarrollará su propia estructura combinatoria. La aparente pobreza de la expresión se debe al escaso movimiento a que se ven reducidos dichos elementos en los límites del espacio pictórico. Y es que el discurso que se inicia en este periodo tiende a acentuar, precisamente, la crisis de significado de los límites. Tenemos una combinatoria que parte de elementos limitados, en un espacio limitado, y cuyo impacto perceptivo en el observador ha de mostrarnos hasta qué punto la presunta simplicidad de la estructura y del uso del color no son sino resultado de una lectura demasiado precipitada de la obra de este artista. 
El análisis de la obra nos permite, en efecto, ver la compleja trama de relaciones y combinaciones entre unos pocos elementos, así como las dramáticas consecuencias que pueden derivarse de este modo de expresión. Pues si bien la estructura hallada en esta época de su vida sirve a Rothko para instalar un nuevo lenguaje, al mismo tiempo dicha estructura acabará por ahogar su capacidad comunicativa, de manera que, al final de su trayectoria vital, la pintura tendrá que crear a su vez un nuevo marco de expresión y unos nuevos modos de significación.

La pintura de Rothko, como dejó dicho en numerosas ocasiones, tenía vocación de transmisión y sus reflexiones escritas acerca del tema confirman la coherencia de su pensamiento en este punto. La desaparición de la figura humana como sujeto pictórico, a lo largo de la década de los años cuarenta, de ningún modo anunciaba una crisis de lo humano, como nos ha recordado Robert Motherwell en una conferencia pronunciada el 6 de febrero de 1970 acerca de las relaciones entre abstracción y humanismo. ${ }^{43}$ Lo que está en crisis no es el ser humano, sino nuestra percepción de lo humano. De lo que la pintura de Rothko nos advierte es de la pobreza de nuestros modos de percibir la realidad, es decir, las emociones, la alegría y el sufrimiento: verdaderos sujetos del arte y de la vida. Por ello, la pintura de Rothko se nos presenta como una reacción violenta a nuestro conocimiento de la realidad y de cuanto somos capaces de ver; porque ciertamente su arte parece destinado a poner en crisis el espacio de realidad del que nuestra percepción se hace cargo. Los elementos visibles de las pinturas de Rothko son espacio y color, que instalados en una realidad ordinaria nos abren, a través de la combinación y la repetición, a un orden invisible que esa misma realidad contiene. Espacio y color, como elementos más esenciales de su pintura, y combinatoria y repetición como modos de comprensión de éstos.

Un cuadro del año 1962, expuesto en el Smart Museum of Art de la Universidad de Chicago (No. 2, 1962; véase la lámina adjunta), ${ }^{44}$ nos da ocasión para situar debidamente los elementos de nuestro análisis. El formato habitual de los cuadros de Rothko, excepto en algunos de los grandes trípticos, es el rectángulo vertical. En este caso se hallan inscritos en él dos rectángulos horizontales que dividen el cuadro en dos partes principales. El rectángulo superior es mayor que el inferior.

${ }^{43}$ R. Motherwell, L'Humanisme de l'abstraction.

${ }^{44}$ Mark Rothko (estadounidense, nacido en Rusia, 1903-1970), No. 2, 1962, medidas: $81 \times 76$ in, $(205.7 \times 193 \mathrm{~cm})$; óleo sobre tela; The David and Alfred Smart Museum of Art, The University of Chicago; donado por Mrs. Albert D. Lasker, 1976.161. 
A diferencia de otras pinturas, cada uno de ellos muestra cierta autonomía definida por las dos grandes secciones o espacios de color. Y sin embargo, aun cuando los espacios quedan delimitados por el color, es éste el que tiende asimismo a difuminar los límites de cada uno de los rectángulos con respecto al fondo en el cual están inscritos. Las declaraciones del artista acerca de la importancia y necesidad del tema en su pintura han sido ocasión para una lectura de los rectángulos como figuras individuales que dan expresión a aquella dimensión subjetiva. Pero me parece difícil aislar la figura del color que la configura, dada la intervención del color en la figuración del tema.

En este cuadro, la falta de definición de los límites, que avanzan sobre el fondo de modo irregular, debido a los trazos de la esponja y del pincel sobre el lienzo, nos hace pensar más bien en el color como soporte de la individualidad figurada por la forma geométrica. La retórica de la individualidad se desplaza de lo formal a lo expresivo: de la geometría al color. En Rothko, la pregunta sobre el tema viene determinada primero por el color, en cuanto que éste afecta la forma del sujeto que se expresa o manifiesta en el cuadro. Si lo que dota de cierta individualidad a la figura es su autonomía frente a otras formas o temas, es decir, si lo que convierte a un sujeto en individuo es su capacidad de separarse de otros - y más en el contexto del significado de "abstracción" en el que nos encontramos-, aquí la mancha de color actúa negativamente respecto de la individualidad formal. Si la figura se difumina, perdiendo de este modo parte de su individualidad, se debe a la acción des-figurativa del color. Pero a medida que el color avanza sobre el fondo de la tela, destruyendo los límites figurativos del rectángulo, el contraste con el fondo se hace mayor, debido a la diferencia cromática del magenta sobre el ocre de la pintura de base en la tela.

Hay que notar que este discurso sobre un sujeto con una doble manifestación, cromática y formal a un tiempo, no lo vamos a encontrar siempre de manera tan expresa; pero la simplicidad de esta obra, en lo que a los elementos se refiere, nos permite hacer un seguimiento de los mismos hasta sus últimas creaciones, aunque éstas se fueran haciendo cada vez menos perceptibles, como por ejemplo en la Rothko Chapel de Houston. ${ }^{45}$

No creo que deba de hablarse de evolución en la pintura de estos años. Hay una evidente evolución o maduración de su concepción dramática de la persona, desde sus primeras obras de tema sacrificial de los años cuarenta a los "Multiforms", pero ya una vez instalado en el nuevo

${ }^{45}$ Véase el importante trabajo de S. Nodelman, The Rothko Chapel Paintings. 
lenguaje de los "Sectionals" (los Multiforms no constituyen un nuevo lenguaje, sino el proceso - destructivo- hacia éste), Rothko va a moverse a tientas. Desde la perspectiva de una hermenéutica que atienda no sólo a la interpretación de significados, sino también al aparecer o a la "presencia", ${ }^{46}$ la evidente crítica al sujeto individual lleva implícita una crisis de la subjetividad, la cual afecta a los modos de visibilidad de la obra de arte, pues si el estado de indiferenciación o ambigüedad de los límites, como una consecuencia en el camino de abstracción, cuya referencia remota es la destrucción de la figura humana, pone en crisis un modo de comprensión de lo humano, en cierto modo también quedan afectados por esta crisis los canales de acceso a la realidad visible, así como también la misma capacidad comunicativa o de transmisión de la obra de arte.

La crisis que manifiesta el cuadro, y que da comienzo con una crisis de los propios límites expresivos, es la que se traslada al observador, también él sujeto que presencia dicha crisis. Aquí el elemento empático es crucial, pues sólo un sujeto en crisis parece que podría reconocer un contexto crítico. Hay una transmisión entre sujetos en crisis. Podemos decir que todo sujeto humano está constitutivamente siempre en crisis, pero lo que aquí importa es la conciencia de esta crisis y si dicha conciencia provoca una percepción interior, o apercepción, que nos abriera a una nueva visibilidad. Gracias a la visión del cuadro, el sujeto que observa descubre en su intimidad un estado de crisis, aun cuando sea necesaria siempre una dispositio por parte del sujeto que busca la verdad de su ser individual.

El rectángulo vertical en el cual se hallan inscritas las dos manchas rectangulares y horizontales de color nos sigue hablando. Ya hemos visto cómo la crisis de los marcos o límites pone al descubierto una crisis del sujeto, y ésta una crisis de los modos de percepción. Quizá también la crisis de los modos de percepción venga señalada por los límites de la percepción y por el sujeto de percepción. ¿Cuál es la capacidad y el alcance perceptivo del sujeto, aniquilado primero por el sacrificio en su papel de figura y dispuesto ahora a su disolución en la mancha de color? El problema vuelve a ser un problema de los límites y de las demarcaciones. Es un problema que afecta al lugar desde el cual el sujeto desfigurado alcanza a percibir y al objeto de su percepción. La disolución del tema o de la figura tiene como consecuencia la indeterminación de los lugares: es decir, pone en crisis la diferencia entre exterior e interior,

${ }^{46}$ En el sentido que han dado a estos términos G. Steiner, Presencias reales, y H.-U. Gumbrecht, Producción de presencia. 
y entre arriba y abajo, lo cual nos conduce a cuestionarnos el papel de la "diferencia" como marco de interpretación y comprensión de la obra de arte. ${ }^{47} \mathrm{Y}$ la crisis de la diferencia nos lleva a situar la cuestión de las "secciones", desde la perspectiva de las analogías, con la esperanza de obtener de ellas el código para descifrar este nuevo lenguaje, pues si lo interior y exterior, como cualquier otra polaridad, no pueden ser ya diferenciados a causa de un sujeto que él mismo carece de identidad contrastante, la dimensión perceptual debe plantearse nuevamente.

Para ver necesitamos un lugar desde el cual poder ver y algo que ver porque se muestre a la mirada. En este periodo parece que Rothko acudió, como modelo para sus cuadros, a las ventanas que Miguel Ángel concibió para el muro de la escalera de la Biblioteca Laurentiana de Florencia. Se trata de ventanas cegadas, donde, en palabras de Rothko, la mirada del lector, atrapado en el interior de la biblioteca, se da de bruces contra el muro. Nada hay fuera, todo está dentro. Y sin embargo no se trata de un espacio sin ventanas. Los marcos actúan como soportes de contemplación. El objeto de contemplación u observación es el propio sujeto que ha iniciado, con la mirada hacia afuera, una salida que no va a encontrar más camino que el de retorno hacia sí mismo. El único objeto de contemplación o de visión posible es el propio sujeto que, en el transcurso de su aventura hacia el exterior, halla la ventana sellada y se ve obligado a recogerse.

El movimiento de separación o diferenciación a que ha dado lugar esa mirada concluye con la conciencia de un estado crítico. Lo que se pone en primera línea en crisis es la distinción entre un aquí y un allí y, así pues, entre la capacidad de distinguir un mundo exterior a la conciencia. Lo que ha entrado aquí en crisis es la conciencia subjetiva frente a un posible marco de realidad exterior. Se hace necesario concebir una dimensión perceptual en la que la distinción exterior e interior no sea relevante, o en la cual el sujeto que percibe lo haga desde un lugar que abarque tanto el afuera como el adentro, puesto que él mismo no se halla en el modo estático de observación. Y aquí es donde hay que abordar de nuevo el cuadro del Smart Museum.

Los dos rectángulos de color se hallan sobre el fondo ocre de la tela, separados por una franja que pertenece al fondo mismo. Toda la base emerge con una luz que atraviesa tenuemente la sección superior, mientras que la inferior permanece opaca por el bermellón. La intersección no es tanto un límite separador, como en muchas otras pinturas, como un recuerdo del fondo primero en el que todo es indistinto e indiferen-

${ }^{47}$ Cfr. T. Crow, “The Marginal Difference in Rothko's Abstraction”. 
ciado. Como si el sujeto que observa este cuadro tuviera que evitar la dualidad obvia de las dos secciones para atender a una realidad más básica o elemental, en la cual el sujeto que percibe ya formara parte de la misma realidad percibida.

Desde el punto de vista de una fenomenología extrema, no hay un afuera del mundo, sino sólo una subjetividad radical. Querría citar aquí, a propósito de esto último, un texto de Michel Henry que acude en nuestra ayuda:

Considerada en su interioridad radical y de este modo en esa Noche abisal en la que no se alza ningún Afuera, la subjetividad no es algo abstracto en el sentido de lo que todavía carecería de realidad, realidad que no podría encontrar sino por la agregación de un elemento exterior, de la exterioridad del mundo. Por el contrario, la subjetividad define esa realidad, esa plenitud del ser, fuera de la cual no hay nada. Y como el exterior por sí mismo no existe, la obra considerada como ese exterior, como ese cuadro que vemos, no puede sino tomar su contenido de la subjetividad de la vida en que se concentra la realidad, la del arte especialmente. ${ }^{48}$

Esta subjetividad está constituida por el impacto emocional de la pintura sobre el observador, con lo cual quedaría destruida toda mediación o representación objetiva. Éste es un aspecto de la obra de Rothko, como de la de otros artistas abstractos, que puede dar resultados muy sorprendentes de cara a una idea de la vida que nos proporciona el arte, en la medida que no representa nada, ningún mundo. Y también nos proporciona una idea de cuanto habría hoy que entender por misterio o invisible. No ya lo situado en un más allá, como es característico del dualismo platónico y que el cristianismo incorporó muy pronto en su mensaje. Una invisibilidad que el arte, como un modo de expresión de la vida, dispone ante nuestra mirada atónita. Se trataría, por tanto, de educar esa mirada que haga posible penetrar la profundidad de las cosas, como decía Rothko, para poder llegar a sus estratos más íntimos, y que haría plausible una invisibilidad mediante lo visible y una sacralidad mediante lo profano.

Tal como lo muestra el último volumen de las obras de Hans Blumenberg, dedicado a sus escritos póstumos, una crítica de la visibilidad debe ser considerada en el campo de una antropología. ${ }^{49}$ Nuestro proyecto se orienta en el desarrollo de una antropología de los sentidos

${ }^{48}$ M. Henry, Ver lo invisible, p. 37.

${ }^{49} \mathrm{H}$. Blumenberg, "Variationen der Visibilität", en Beschreibung des Menschen, pp. $777-895$. 
espirituales, pero ya no en el modo en que la concibió Orígenes, desde un sentido analógico con los sentidos corporales. El reto consiste ahora en volver a definir qué es "espiritual", en la línea, por ejemplo, de como lo hizo en el siglo XIV Ramon Llull, cuando hablaba de "sentidos intelectuales-espirituales" (cogitación, conciencia, apercepción, coraje y sutileza). Una antropología de este tipo garantizaría que lo invisible tuviera una correspondencia, a nivel hermenéutico, con lo que es visible; es decir, que la estética asumiría el estatuto de invisibilidad o el de la ausencia. De esta manera, una estética apofática se presentaría como un espacio de convergencia entre el pensamiento filosófico, el arte y la hermenéutica del misterio. Pero todo ello es una labor que nos queda todavía por hacer. ${ }^{50}$

\section{BIBLIOGRAFÍA}

Altizer, T.J.J., Living the Death of God. A Theological Memoir, State University of New York Press, Albany, Nueva York, 2006.

Baßler, M. y H. Châtellier (comps.), Mystique, mysticisme et modernité en Allemagne autour de 1900/Mystik, Mystizismus und Moderne in Deutschland um 1900, Presses Universitaires de France, París, 1998.

Belting, H., Bild-Anthropologie: Entwürfe für eine Bildwissenschaft, Fink Verlag, Munich, 2001.

— Bild und Kult, Beck, Munich, 1991.

Benz, E., Les Sources mystiques de la philosophie romantique allemande, Vrin, París, 1987.

Blumenberg, H., Beschreibung des Menchen, Suhrkamp, Fráncfort del Meno, 2006.

Bohrer, K.-H., Ästhetische Negativität, Hanser, Munich, 2002.

Castelli, E., Lo demoníaco en el arte, trad. María Cóndor, Siruela, Madrid, 2007. Certeau, M. de, La Fable mystique, Gallimard, París, 1982. [Versión en castellano: La fábula mística, trad. de L. Colell, Siruela, Madrid, 2007.]

Cirlot, V., Hildegard von Bingen y la tradición visionaria de Occidente, Herder, Madrid, 2005.

Cirlot, V. y A. Vega, Mística y creación en el siglo xx, Herder, Barcelona, 2006.

Cirlot, V. y B. Garí, La mirada interior. Místicas y visionarias en la Edad Media, Siruela, Madrid, 2008.

Crow, T., "The Marginal Difference in Rothko's Abstraction", en Phillips y Crow, Seeing Rothko, pp. 25-39.

Deleuze, G., Cinéma I: L’image-mouvement, Les Éditions du Minuit, París, 1983.

—_ Francis Bacon. Lógica de la sensación, trad. José Vázquez Pérez, Paidós, Barcelona, 1991.

${ }^{50}$ Un primer intento se encuentra en mi Tratado de los cuatro modos del espíritu. 
Derrida, J., Cómo no hablar, trad. P. Peñalver, Anthropos, Barcelona, 1997.

D'Ors, E., Lo barroco, Tecnos/Alianza, Madrid, 2002.

Eliade, M., El vuelo mágico, ed. y trad. V. Cirlot y A. Vega, Siruela, Madrid, 1995.

Frazer, J., La rama dorada. Magia y religión, trad. Elizabeth y Tadeo I. Campuzano, Fondo de Cultura Económica, México, 1991.

Gianetti, C., Estética digital. Sintopía del arte, la ciencia y la técnica, L'Angelot, Barcelona, 2002.

Gombrich, E.H., Aby Warburg. An Intelectual Biography, Phaidon Press, Oxford, 1986.

Graf, A., The Cinema of Wim Wenders, Wallflower Press, Londres/Nueva York, 2002.

Gruber, B., "Mystik, Esoterik, Okkultismus: Überlegungen zu einer Begriffsdiskussion", en Baßler y Châtellier (comps.), Mystique, mysticisme et modernité en Allemagne autour de 1900, pp. 27-38.

Gumbrecht, H.-U., Producción de presencia, trad. Aldo Mazzuchelli, Universidad Iberoamericana, México, 2005.

Haas, A.M., Kunst rechter Gelassenheit, Peter Lang, Berna, 1996.

—-, "Las imágenes explosivas de Dios", en Er. Revista de Filosofía, número especial, V. Cirlot y A. Vega (comps.), Nada, mística y poesía, Sevilla, 1998.

Halbertal, M. y A. Margalit, Idolatría, trad. M. Mizraji, Gedisa, Barcelona, 1992.

Heidegger, M., "Der Ursprung des Kunstwerkes", en Holzwege, Vittorio Klostermann, Fráncfort del Meno, 1980, pp. 1-72.

—, "Wozu Dichter?", Holzwege, Vittorio Klostermann, Fráncfort del Meno, 1980, pp. 265-316.

—, Phänomenologie des religiösen Lebens (Gesamtausgabe, vol. 60), Vittorio Klostermann, Fráncfort del Meno, 1995.

Henry, M., Ver lo invisible, trad. M. Tabuyo y A. López, Siruela, Madrid, 2008.

Hoberg, A., Kandinsky. Absolut. Abstrakt, ed. Helmut Friedel, Prestel, Munich, 2008.

Jüngel, E., Dios como misterio del mundo, trad. F. Carlos Vevia, Sígueme, Salamanca, 1984.

Kandinsky, W., De lo espiritual en el arte, trad. G. Dieterich, Paidós, Barcelona, 1996.

Kierkeggard, S., Temor y temblor, trad. V. Simón Merchán, Tecnos, Madrid, 2001.

Kitzinger, E., The Art of Bizantium and the Medieval West: Selected Studies (c. V et VII), Indiana University Press, Bloomington/Londres, 1976.

Kolakowski, L., Chrétiens sans Église. La conscience religieuse et le lien confessionel au XVII siècle, Gallimard, París, 1969.

Maestro Eckhart, El fruto de la nada, 6a. ed., ed. y trad. A. Vega, Siruela, Madrid, 2007.

Marion, J.-L., De Surcroît. Études sur les phénomènes saturés, Presses Universitaires de France, París, 2001.

Merleau-Ponty, M., L'OEil et l'esprit, Gallimard, París, 1964.

Mersch, D., Ereignis und Aura, Suhrkamp, Fráncfort del Meno, 2002. 
Mersch, D., Was sich Zeigt. Materialität, Präsenz, Ereignis, Wilhelm Fink Verlag, Munich, 2002.

Motherwell, R., L'Humanisme de l'abstraction, L'Echoppe, París, 1991.

Nietzsche, F., El nacimiento de la tragedia, trad. A. Sánchez-Pascual, Alianza Editorial, Madrid, 2000.

Nishitani, K., La religión y la nada, trad. R. Bouso-García, Siruela, Madrid, 1999.

Nodelman, S., The Rothko Chapel Paintings, University of Texas Press, Austin, 1997.

Oteiza, J., "Carta a los artistas de América", en Interpretación de la estatuaria megalítica americana, ed. M. Muñoz, Fundación J. Oteiza, Pamplona, 2007, pp. 259-299 (Edición crítica de la obra de J. Oteiza, vol. 3).

- , Quousque tandem....!, ed. crítica de A. Vega, en colaboración con Jon Echeverría, Fundación J. Oteiza, Pamplona, 2007 (Edición crítica de las obras de J. Oteiza).

Ossola, C., "Caminos de la mística: siglos XVII-XX", en Cirlot y Vega, Mística y creación en el siglo $x x$, pp. 13-62.

Otto, R., Lo santo, trad. F. Vela, Alianza Editorial, Madrid, 1980.

Polcari, S., Abstract Expressionism and the Modern Experience, Cambridge University Press, Cambridge, 1991.

Phillips, G. y T. Crow (comps.), Seeing Rothko, Getty Center, Los Ángeles, 2005.

Rothko, M., The Artist's Reality. Philosophies of Art, ed. C. Rothko, Yale University Press, New Haven/Londres, 2004.

— Writings on Art, ed. M. López-Remiro, Yale University Press, New Haven/Londres, 2006..

Rowell, M. y T. Badiola, Oteiza: mito y modernidad, catálogo de exposición, Guggenheim, Bilbao, 2004.

Saxl, F., "La historia de la Biblioteca de Warburg (1886-1944)", en E.H. Gombrich, Aby Warburg. Una biografía intelectual, pp. 299-310.

Sepp, H.-R., "Annährungen an die Wirklichkeit. Phänomenologie und Malerei nach 1990", en H.-R. Sepp (comp.) Edmund Husserl und die Phänomenologische Bewegung, Karl Alber, Friburgo de Brisgovia, 1988, pp. 77-93.

Steiner, G., Presencias reales, trad. Juan Gabriel López Guix, Destino, Barcelona, 1991.

Taylor, M.C., After God, The University of Chicago Press, Chicago/Londres, 2007.

- Disfiguring. Art, Architecture and Religion, The University of Chicago Press, Chicago/Londres, 1992.

Vega, A., "Antoni Tàpies: Negatio, Negationis. Un espacio de meditación y silencio", en Cirlot y Vega, Mística y creación en el siglo XX, pp. 241-266.

—_, Arte y santidad. Cuatro lecciones de estética apofática, Cátedra J. Oteiza, Universidad Pública de Navarra, Pamplona, 2005.

__ , "Mística y estética en el pensamiento de Jorge Oteiza", en M. Rowell y X. Badiola (comps.), Oteiza. Mito y Modernidad, Bilbao, Guggenheim, 2004, pp. 65-83.

Diánoia, vol. LIV, no. 62 (mayo 2009). 
Vega, A., Passió, meditació i contemplació. Sis assagis sobre el nihilisme religiós, Empúries, Barcelona, 1999.

_- Ramon Llull y el secreto de la vida, Siruela, Madrid, 2002; versión en inglés: Ramon Llull and the Secret of Life, trad. J.W. Heisig, Herder and Herder, Nueva York, 2003.

—_ Tratado de los cuatro modos del espíritu, Alpha Decay, Barcelona, 2005.

_- Zen, mística y abstracción. Seis ensayos sobre el nihilismo religioso, Trotta, Madrid, 2002.

Viola, B., The Passions, ed. J. Walsh, J.P. Getty Publications, Los Ángeles, 2003. Vries, H. de, Philosophy and the Turn to Religion, The Johns Hopkins University Press, Baltimore/Londres, 1993.

Wagner-Egelhaaf, M., "Die mystische Tradition der Moderne. Ein unendliches Sprechen", en Baßler y Châtellier (comps.), Mystique, mysticisme et modernité en Allemagne autour de 1900, pp. 41-57.

Zima, P.-V., La Négation esthétique, L'Harmattan, París, 2002.

Recibido el 14 de julio de 2008; aceptado el 19 de noviembre de 2008. 